\title{
Give Me a Reason to Dig Minecraft and Psychology of Motivation
}

\author{
Alessandro Canossa, Josep B. Martinez, Julian Togelius
}

\begin{abstract}
Recently, both game industry professionals and academic researchers have started focusing on playergenerated behavioral data as a mean to gather insights on player psychology through datamining. Although some research has already proven solid correlations between ingame behavior and personality, most techniques focus on extracting knowledge from in-game behavior data alone. This paper posits that triangulating exclusively behavioral datasets with established theoretical frameworks serving as hermeneutic grids, may help extracting additional meaning and information. The hermeneutic grid selected for this study is the Reiss Motivation Profiler and it is applied to behavioral data gathered from Minecraft players.
\end{abstract}

\section{INTRODUCTION}

"Uncounted gigabytes of information are now available at a finger's touch on a keyboard, cached in digital memories, out of context. Our problem is not the scarcity of information, but the overwhelming challenge of sorting it, understanding it, and finding relevance, meaning and truth within data".

[Neil Gaiman - "The Absolute Sandman, Vol. 1"]

Potentially, every single interaction within a game can generate data. Monitoring game data to gain better understanding has become a widespread industry practice with the multiple intents of improving the design, streamlining production processes and maximizing revenues. For revenue maximization and design improvement, a deeper understanding of player behavior has become essential. A number of methods and techniques have already been used to interpret player data, from simple co-occurrences of game events [10] to more complex clustering techniques that can identify groups of players with similar behavior $[9,16]$. In this paper we argue that making use of an established hermeneutic grid from psychology can greatly improve understanding of player behavior.

The hermeneutic grid chosen to help interpreting and making sense of player-generated data for this study is a psychological theory of motivation derived from Reiss'

A. Canossa is with Northeastern University, Boston, MA 02115 USA (email: a.canossa@neu.edu)

J. B. Martinez is with Gameloft, Madrid, 28009 Spain (e-mail: josep.martinez@gameloft.com).

J. Togelius is with the IT University of Copenhagen, 2300 Denmark (email: julian@togelius.com). work $[18,19]$. There have already been a number of studies attempting to use external theoretical constructs from psychology to prove correlations between in-game behavior and players' personality $[26,27,28,29,30]$ but very few have attempted to prove correlations with articulated motivation theories beyond mere intrinsic or extrinsic rewards $[4,6]$. Yee has proposed and validated a model of player motivations based on survey data from Everquest players $[23,24]$ but the model is not based on external theoretical framework, instead it is derived from within the possibility space offered by the game, hence would not provide insights on correlation between in-game and out-ofgame behaviors.

Utilizing data gathered from Minecraft players and a motivation survey administered to the same population, this study attempts first of all to prove that there are correlations between in game behavior and life motives or basic desires. Lastly, advanced machine learning techniques such as decision trees, Gaussian processes and support vector machines, are used to predict life motives from multiple ingame variables.

\section{MINECRAFT DESCRIPTION}

Minecraft [31] is a multiplayer sandbox game focused on creativity, building and survival. Players are asked to acquire resources and survive a hostile environment and must maintain their health and hunger at acceptable levels or the avatar might die and drop all items in the inventory. The core gameplay revolves around construction, Minecraft can be played in single and multiplayer mode with three variants: creative, where players have unlimited resources, no threats and can fly freely, survival, where players are challenged by life-threatening creatures every night, must search for resources, craft items, and can gain levels and hardcore, similar to survival but players only have one life. The game world is procedurally created with cubes arranged in a fixed grid pattern. Cubes are made of different materials, such as dirt, stone, etc. Players can gather these materials and either place them in the world to create various constructions or use them to craft various items. The rationale behind the selection of Minecraft as a testbed is that being an open world with no scripted goal, it allows a very wide possibility space in terms of player behavior. Furthermore the game automatically logs gameplay behavior in the form of gameplay metrics stored locally on 
the client's machine in the file "stats_username_unsent.dat". Minecraft does not track all the events in the game, for instance there is no trace of the number of times the avatar eats food. The file log stores three groups of events: "general", "achievements" and "blocks". The first group tracks general variables: from the number of times the game has been loaded to the number of fish caught or the distance covered while walking. The group "achievement" tracks the number of times a certain game condition has been met: from the number of times a player has reached the end of the game to the number of times the inventory was opened. The group "blocks" stores 3 types of events: attainment (number of times that items and blocks are mined or crafted), use (number of times that items are used and blocks placed) and depletion (number of times that items are broken).

\section{Psychology OF Motivation}

Motivation is defined both as reasons for behaving in a particular way and a desire to do something. Motivation has long been understood and divided into two types: intrinsic (internal) motivation and extrinsic (external) motivation [8, 21]. Extrinsic motivation is a drive to perform an activity in order to attain an outcome not part of the activity itself and not generated within the performer. Intrinsic motivation is rooted in the enjoyment of the goal-directed actions themselves rather than relying on external pressure, it consists of performing actions that are inherently interesting or enjoyable. Since Herzberg's seminal book "The motivation to work" [15] intrinsic and extrinsic motivations have been considered separated entities. Atkinson layered intrinsic motivation as need to achieve and need to avoid failure, a maximizing and minimizing approach $[32,33]$. Bandura [1, 2, 3] introduced the core concept of selfefficacy as the belief that a person has on the ability of performing a particular task, showing how people by default prefer a feeling of self-efficacy rather than failure avoidance. Reiss [34] believes that intrinsic - extrinsic motivation is an invalid distinction and compares it to a modern version of mind-body dualism, where intrinsic motives (e.g., curiosity, self-determination) are mind related, while extrinsic motives (e.g., hunger, sex) are related to the body. Instead he assets that there are 16 intrinsic motives (or "needs") and no extrinsic motives. Because of this reason, Reiss motivation theory has been chosen as the hermeneutic grid for this study. Furthermore, Reiss' motivation theory, differently from Maslow's [35], takes into account individual differences while the latter generalizes motivation as a single factor applicable to everybody only acknowledging individual differences as exceptions in the hierarchy of needs.

\section{A. Steven Reiss and the 16 Life Motives}

In this study the 16 fundamental motives from the Reiss Motivation Profile (RMP) have been chosen rather than the Five-Factor Model (FFM) of personality [7] for two main reasons. The FFM posits that there is a structure to individual differences in human behavior and the personality traits can be reduced to five orthogonal factors. These factors have been derived from the English lexicon since, as Goldberg states, "those individual differences that are most significant in the daily transactions of persons with each other become encoded into their language" [12]. The 16 fundamental motives bypass the linguistic bias intrinsic in the FFM lexical hypothesis. Furthermore, McCrae argues that only 5 factors may not be enough to express all the individual differences amongst people [17]. In addition to that, since personality consists of recognizable and recurring emotional, rational and behavioral patterns, it represents a composite construct that might be too large to suggest actionable information while designing actions and goals in games. Summarizing, it is possible to say that personality is a construct that attempts to describe what people might chose to do, while motivation attempts to infer why they do it. Reiss argues that psychodynamic theories explain personality as forms of mental illness, what Freud named "the psychopathology of every day"; Freudians blur the distinction between what is normal and what is abnormal and believe that "dark, unconscious mental forces that originated during childhood cause personality traits, personal troubles, and mental illness". Reiss defends the concept of "Normal Personality" [18] declaring that personality is about individuality and how those individuals are motivated by a variety of intrinsically held values. In order to satisfy those values, or basic desires, the individual creates habits. A personality trait is the set of habits focused into fulfill a single basic desire. Reiss and his team performed psychometric research and subsequent behavior validation and discovered 16 basic desires that drive the human behavior: Acceptance; the desire for approval and to avoid criticism; Curiosity, the desire for knowledge; Eating, the desire for food; Family, the desire to raise one's own children; Honor, the desire to obey traditional moral code; Idealism, the desire for social improvement and justice; Independence, the desire for autonomy and self-reliance; Order, the desire for structure and organization; Physical Activity, the desire to move one's muscles; Power, the desire of influence, leadership; Romance, the desire for courting and sex; Saving, the desire to collect, valuing frugality; Social Contact, the desire for friendship; Status, the desire for prestige and attention; Tranquility, the desire for inner peace avoiding anxiety and fear; Vengeance, the desire to get even, compete and win.

Everybody embraces those 16 basic desires, but not everybody has the same intensity, the difference in intensity 
generates different personalities and behaviors. The Reiss Motivation Profile (RMP) is a tool engineered to estimate how an individual prioritizes the basic desires. The Reiss Motivation Test Profiler (RMTP) is a tool to reveal the RMP and the personality traits derived from the basic desires.

These basic desires share a number of qualities: universal motivation - the basic desires motivate everyone; psychological needs - the basic desires can be satiated only temporarily, thus they become life motives; intrinsic motivation - the pursuit of the desire for no other reason than the desire itself; intrinsic values - the basic desire expresses an intrinsic value; psychological significance they are not biological needs.

The basic desires have different intensities: strong intensity (represented by the upper $20 \%$ of the total population), average intensity (it corresponds to the $60 \%$ of the general population) and weak intensity (constituted by the lowest $20 \%$ of the population). The 16 motivations address a much lower level of representation; personality types emerge as patterns of strong and weak basic desires.

This study attempts to associate the 16 basic desires with behavioral clues of players interacting with the game Minecraft and logged through the client.

\section{Player Modeling and Game Data Mining}

Over the last decade, there has been a substantial and increasing research activity in modeling players quantitatively, which means based on data acquired from in-game or real-life activities. These studies use statistical or machine learning methods to establish relationships between features that describe player activity, preferences, affect, personality or other aspects.

Two recent survey papers provide overviews and taxonomies of this field. Yannakakis and Togelius [36] focus on methods for modeling the experience of the player, and categorize such methods mainly according to the source of the data: subjective (questionnaires of various kinds), objective (based on physiological, psychophysiological or other physical measurements such as skin conductivity or analysis of facial expressions) and gameplay-based (actions the player takes in the game). Within each of these categories, several alternatives are listed, such as whether the measurements are structured according to some model and whether the questionnaires deal with preferences or ratings.

Smith et al. [37] provide a very broad view of player modeling and apart from the source of the data, they also categorize player modeling methods according to three other facets. These are scope (individual, class, universal and hypothetical), purpose (generative and descriptive) and domain (human actions and game reactions). The models that we describe here are produced from a combination of subjective (questionnaires) and gameplay-based data, and could be categorized as universal, descriptive models of reactions.

Whereas much early work focused on analyzing small data sets from testbed games played in laboratory conditions, some recent work have attempted to induce player models using machine learning from massive logs of player data gathered from commercial games via telemetry. For example, Canossa et al. [11] used self-organizing maps to identify player types among tens of thousands of players of the modern action-adventure game Tomb Raider: Underworld; in a follow-up study, Mahlmann et al. [16] managed to predict future behavior of players, including at what level players stop playing the game, based only on early-game player behavior.

Some other recent work has focused on modeling the association between in-game behavior and out-of-game behavior and attitudes. Perhaps the most well-known examples is Yee et al. [26] study of personality types among World of Warcraft (WoW). Yee and team found that the types of character WoW players chose to play, and what they choose to do in the game, correlate significantly with their personalities as measured by the Big 5 personality test and taxonomy. Spronck [38] similarly finds correlations between personality features and aspects of playing behavior in players of Fallout 3.

Canossa [6] attempted to test for correlations between affordances in Minecraft and player behavior; the study focused mostly on testing the strength of game designers' qualitative assumptions when asked to hypothesize which of Minecraft's game mechanics would be the most fitting to describe each of the 16 motivations.

\section{Methodology}

Players from all around the world were asked to fill a survey online. The survey contained 4 sections: General, Upload, RMTP and Feedback. The general part contained items related to the participant: age, country, gender, education and gaming habits. The upload section included instructions to upload Minecraft's .dat file to the server. RMTP included the 96 test questions from the Reiss Motivation Profile [18]. The last section asked for participants' feedback.

The survey was advertised in several Minecraft forums from different countries including the official Minecraft page. It was also advertised in several Facebook communities, Twitter accounts, and schools bulletin boards.

100 surveys were collected after 4 months. Surveys containing incorrect files or missing entries in the motivation test were rejected. After the initial data verification, 92 surveys were selected: 84 in English and 8 in Spanish.

The data collected from the Minecraft logs was 
preprocessed. Considering that total play time differed widely, all variables were normalized preventing biased results due to different amount of time spent by players. Lastly, surveys with less than 30 minutes of playing time were rejected as it is considered there was not enough information, leaving 86 participants. Each survey produced 659 parameters: 1 x ID, $96 \times$ Reiss motivation test answers, 16 x Reiss Motivation profile, 546 x Minecraft parameters. The 86 surveys produced 56.674 values to analyze.

\section{RESULTS}

\section{A. Minecraft Descriptive Statistics}

Participants come from 21 different countries, the top three are: Spain (25,58\%), United States $(17,44 \%)$ and Denmark (11.3\%). The average age is 20.99 , ranging from 12 to 46 . The high number of male players $(91.85 \%, n=79$ versus $8,14 \%, n=7)$, matched previous results [24]. On average participants declared to have played 19.27 hours each week confirming previous findings [24]. The selfreported measure of play time often diverges from the monitored value, possibly because of a negative social bias. For example a player declaring 0 hours per week actually played the most (450 hours in total), confirming a study that compared self-reported use and actual use among players showing systematic differences [39]. The survey shows a high level of expertise in the game: $4.65 \%$ of the players play only Minecraft, and $41.86 \%$ play more games but Minecraft is their main game. Minecraft players tend to have medium grade of studies. $76,74 \%$ have finished or are studying High school or Bachelor studies. School level is 6,98\%, High School 38,37\%, Bachelor, 38,37\%, Master Level $10,47 \%$ and $\mathrm{PhD}$ is $5,81 \%$. The level of studies is positively correlated with age, so the results are as expected.

The research correlates 571 variables. It is not very practical to show descriptive statistics about all of them so only general statistics are included in table 1.

TABLE I

Summary of General Statistics in Minecraft

\begin{tabular}{|l|l|l|l|l|}
\hline Statistic & Mean & SD & Min & Max \\
\hline Hours Played & 53,37 & 67,64 & 0,69 & 450,54 \\
\hline Times Played & 62,17 & 121,15 & 0,00 & 617,00 \\
\hline Worlds Played & 8,20 & 13,60 & 0,00 & 90,00 \\
\hline Saves Loaded & 32,56 & 91,84 & 0,00 & 563,00 \\
\hline Multiplayer joins & 110,94 & 129,15 & 0,00 & 571,00 \\
\hline Games quit & 113,86 & 139,65 & 1,00 & 613,00 \\
\hline Distance Walked & 183274,4 & 290325,01 & 1014,58 & 1924954,44 \\
\hline Distance swam & 4565,62 & 6815,38 & 1,16 & 46683,79 \\
\hline Distance Fallen & 7303,75 & 13662,61 & 0,00 & 89619,87 \\
\hline Distance climbed & 1487,33 & 2916,28 & 0,00 & 24624,31 \\
\hline Distance Flown & 36733,01 & 55700,29 & 1,07 & 311901,45 \\
\hline Distance dove & 2455,68 & 3608,00 & 0,00 & 22267,80 \\
\hline DistanceMinecart & 4203,60 & 15928,94 & 0,00 & 135254,50 \\
\hline Distance by boat & 3532,47 & 6238,62 & 0,00 & 28066,95 \\
\hline Distance by pig & 8,73 & 28,26 & 0,00 & 214,39 \\
\hline Jumps & 18616,38 & 26062,71 & 109,00 & 174052,00 \\
\hline Items Dropped & 331,87 & 665,14 & 0,00 & 4651,00 \\
\hline Damage Dealt & 14725,50 & 28659,31 & 0,00 & 216790,00 \\
\hline
\end{tabular}

\begin{tabular}{|l|l|l|l|l|}
\hline Damage taken & 14335,29 & 45967,93 & 0,00 & 367506,00 \\
\hline Deaths & 4,05 & 11,90 & 0,00 & 80,00 \\
\hline Mob kills & 734,19 & 1272,09 & 0,00 & 7361,00 \\
\hline Player Kills & 0,07 & 0,45 & 0,00 & 4,00 \\
\hline Fish Caught & 4,51 & 10,03 & 0,00 & 51,00 \\
\hline
\end{tabular}

On average participants spent 53.37 hours in total. Minecraft does not encourage for aggressive gameplay against other players, which is confirmed by the fact that the player kills are very low with an average of 0,07 and max value of 4 . In table 1 is possible to observe the difference between players. For instance: players who only play multiplayer (multiplayer joins $=$ high value and worlds created/ played $=0$ ) versus single player (multiplayer $=0$ and world created/played $=$ high value) and players who only play creative mode (mob kills and damage dealt/received $=0$ ) versus those players who play survival mode (damage dealt/received/number of deaths = value).

\section{B. Motivations Descriptive Statistics}

Table 2 shows descriptive statistics for the RMPT. Mean and Standard Deviation were calculated for each of the players' basic desires.

TABLE II

Average player's profile (** strongest, $*>0.5$ stronger than average)

\begin{tabular}{|l|l|l|}
\hline Statistic & Mean & SD \\
\hline Acceptance & $-0,6279^{*}$ & 1,364 \\
\hline Curiosity & $0,9767^{* *}$ & 1,355 \\
\hline Eating & 0,3140 & 1,191 \\
\hline Family & 0,0698 & 1,196 \\
\hline Honor & $0,5698^{*}$ & 1,164 \\
\hline Idealism & $0,6977^{*}$ & 1,311 \\
\hline Independence & $0,6977^{*}$ & 1,293 \\
\hline Order & $-0,4302$ & 1,306 \\
\hline Physical activity & $-0,1977$ & 1,509 \\
\hline Power & $-0,0930$ & 1,271 \\
\hline Romance & $-0,2093$ & 1,209 \\
\hline Saving & $0,6860^{*}$ & 1,119 \\
\hline Social contact & $-0,0233$ & 1,346 \\
\hline Status & $-0,9767^{* *}$ & 1,208 \\
\hline Tranquility & $-0,0930$ & 1,113 \\
\hline Vengeance & $-0,4070$ & 1,349 \\
\hline
\end{tabular}

The average Minecraft player profile has 7 basic desires that differentiate it from the average person. Two of them are clearly more noticeable than the rest as they are close to the value 1 or -1 : Strong Curiosity and Weak Status.

A way to understand the relationship between the game and the average player profile is to assume that players are trying to satisfy their basic desires while playing the game. Both of the identified basic desires seem to align with the inscribed affordances provided by the game design.

Curiosity is "the universal desire for intellectual activity, learning, creating... people with strong basic desire for curiosity are easily bored and need frequent intellectual stimulation; they may be oriented to creative, imaginative ideas"[18]. The world in Minecraft is created procedurally; it is almost an infinite world. It includes different areas and materials to discover. The game itself is a mystery, when players start the game there are no clues about what to do; goals, enemies, actions: the whole game is about discovery. 
Players have a wide range of ways to investigate research and create. Minecraft affords a large freedom for expressing curiosity.

Status is "the desire for social standing based on wealth, title, social class"[18]. People with weak desire for status are unimpressed about all the previously mentioned factors. A weak desire for status is easily embodied by the game's design philosophy as there are really no mechanics centered on display of status, except maybe for gold armor.

There are 5 further basic desires that score above and close to 0.5 or below and close to -0.5 : Weak Acceptance, Strong Honor, Strong Idealism, Strong Independence, Strong Saving.

Acceptance is "the universal desire not to be criticized and rejected"[18] Minecraft players tend to be selfconfident, making them prone to try new things, as they do not care about what others think or how they should behave in front of others. The lack of clear gameplay related to this basic desire fits with the weak basic desire.

Honor is "the desire to behave morally, honor motivates loyalty to parents and clan" [18]. Minecraft players tend to have strong honor, so they are willing to join clans. Although clan formation has not been studied in this research since it is not performed in a formalized, accountable manner, the existence and extended use of a multiplayer mode, several web forums (http://minecraft.net/community), Facebook groups and even a conference held yearly (http://www.minecraftwiki.net/wiki/MineCon) seem to point to the fact that Minecraft players form a committed community and are prone to join clans.

Idealism is "the desire to improve society" [18]. Minecraft players tend to have a strong basic desire for idealism. People with strong basic desire for idealism tend to "have traits of altruistic, dreamer, involved"[18]. Minecraft game design is the paradigm of creation for the sake of creation. Minecraft player can satisfy the desire of building a better or ideal place.

Independence is "the universal desire for selfreliance...satisfaction produces the joy of personal freedom" [18]. Minecraft players tend to have a strong desire of Independence and "personal freedom is everything to them... it may be very important to do things in their way...in animals, independence spreads the search for food over a large geographical extension" [18]. This fits with the game design of survival mode.

Saving is "the desire to collect things" [18], it can be any kind of object. Minecraft player tends to have a strong basic desire for saving, meaning they are collectors and they hate throwing things away. Minecraft fits completely with that strong desire. Analyzing the average Minecraft player profile and the game design it is possible to observe the relationship between the motivational traits and how they are satiated through the game mechanics. This opens an interesting question for further exploration. Is it possible to establish a psychological profile associated to a game and predict the appeal for certain players comparing their motivational profiles?

\section{Correlations Between Motivations and Behavior}

In order to find the relationship between the basic desires and the in-game behavior, Pearson correlation was applied between the 16 basic desires and the 546 Minecraft features collected from the game data. 437 correlations were nominally expected at a significance level of $\mathrm{p} 0.05$ but only 423 correlations were found out of $8736(4,84 \%)$. Lower levels of significance show better results, 87 correlations were nominally expected at a significance level of $p 0.01$; 95 were found. 9 correlations were expected at $p<0.001$ and 11 were found. However, this investigation was performed on unprocessed data, where many features might be essentially meaningless. In a complementary investigation, all features with values of 0 for more than half of all instances were removed. This left 170 features and a much better ratio of actual to expected significant correlations: 162 (136 expected) for $\mathrm{p}<0.5,49$ (27) for $\mathrm{p}<0.1$ and 8 (3) for $\mathrm{p}<0.01$. The data set contains more significant correlations than could be expected according to the null hypothesis. The best 10 correlations are shown in table 3 . TABLE III

Ten best correlations between motivations and behaviors

\begin{tabular}{|l|l|l|l|}
\hline Basic Desire & Game Feature & Coefficient & Significance \\
\hline independence & The End (entering) & -0.371 & 0 \\
\hline curiosity & Cobblestone Used & 0.365 & 0.001 \\
\hline curiosity & Stone Shovel broken & 0.36 & 0.001 \\
\hline curiosity & Stone Axe Crafted & 0.358 & 0.001 \\
\hline tranquility & Fence gate crafted & 0.358 & 0.001 \\
\hline curiosity & Stone Shovel used & 0.355 & 0.001 \\
\hline status & Cactus Mined & -0.353 & 0.001 \\
\hline independence & The End (achievement & -0.345 & 0.001 \\
\hline family & Gold Sword used & -0.34 & 0.001 \\
\hline curiosity & Torch Mined & 0.339 & 0.001 \\
\hline
\end{tabular}

The End (entering) is an achievement where the player has to locate the End and enter a portal. Cobblestone is a common block used for creating various items. It is commonly used to create walls for constructions with a medieval appearance. Shovels are used to dig some materials faster. A shovel is not required to advance forward in the game. Stone shovel has medium durability and medium/low effectiveness. Axes are tools used to ease the process of collecting wood, but are not required to gather wood blocks. They can also be used on mobs and players as a weapon, but do less damage than swords of the same material. A fence gate is a block that functions similarly to a door but it is designed for use in fence lines. A Cactus is a block that is found naturally in deserts, it deals damage is touched. Swords are crafted items used to damage mobs, other players, or to block attacks. Swords can also destroy certain blocks faster than any other tool. Gold Swords are least effective and deadly. The End 
(achievement) entails defeating the ender dragon and entering the Exit Portal, considered to be the prescribed winning condition for the game. Torches are items that emit light. They are used to explore and to secure areas from enemies.

\section{Motivations and Correlated Features}

Each of the basic desires was correlated against the 546 Minecraft statistics. The number of nominally expected significant correlation is 27.3 at the significance level $p$ 0.05. Six traits showed significant correlations above the nominally expected: curiosity, saving, honor, idealism, vengeance and family (table 4). Table 5 shows all game features correlated for each motivation factor.

TABLE IV

Number of correlations per motivation factor

(*above expectation)

\begin{tabular}{|l|l|l|l|l|l|}
\hline & $\mathbf{p . 0 5}$ & $\begin{array}{l}\text { Small } \\
\text { corr. }\end{array}$ & $\begin{array}{l}\text { Medium } \\
\text { corr. }\end{array}$ & max & min \\
\hline acceptance & 13 & 13 & 0 & -0.297 & -0.217 \\
\hline curiosity & $58^{*}$ & 49 & 9 & 0.365 & -0.213 \\
\hline eating & 23 & 21 & 2 & 0.332 & -0.212 \\
\hline family & $31^{*}$ & 24 & 7 & -0.34 & 0.212 \\
\hline honor & $38^{*}$ & 33 & 5 & 0.336 & 0.213 \\
\hline idealism & $34^{*}$ & 31 & 3 & -0.335 & -0.213 \\
\hline independence & 21 & 19 & 2 & -0.371 & -0.213 \\
\hline order & 17 & 17 & 0 & -0.283 & 0.212 \\
\hline physical activity & 14 & 14 & 0 & 0.295 & 0.212 \\
\hline power & 16 & 14 & 2 & -0.333 & 0.214 \\
\hline romance & 18 & 14 & 4 & 0.329 & 0.214 \\
\hline saving & $44^{*}$ & 40 & 4 & 0.323 & 0.213 \\
\hline social contact & 23 & 22 & 1 & -0.332 & -0.213 \\
\hline status & 25 & 23 & 2 & -0.353 & -0.216 \\
\hline tranquility & 13 & 11 & 2 & 0.358 & -0.22 \\
\hline vengeance & $35^{*}$ & 32 & 3 & 0.312 & -0.212 \\
\hline & & TABLE V & \\
\end{tabular}

Game features and motivation coefficient of correlation

(* significant at p.01, ** significant at p.001)

( $\mathrm{M}=$ Mined, $\mathrm{C}=$ Crafted, $\mathrm{U}=$ Used, $\mathrm{D}=$ Depleted)

\begin{tabular}{|l|l|l|l|}
\hline Acceptance & Curiosity & Eating & Family \\
\hline Bookshelf M & Cobblestone P & Compass C & Gold Sword U \\
$-0.297^{*}$ & $0.365^{* *}$ & $0.332^{*}$ & $-0.34^{* *}$ \\
\hline Mycelium M & Stone Shovel D & Bricks M & Gold Sword D \\
0.256 & $0.36^{* *}$ & $-0.326^{*}$ & $-0.334^{*}$ \\
\hline Fire Charge U & Stone Axe C & Vines P & Cobblestone M \\
0.253 & $0.358^{* *}$ & $-0.297^{*}$ & $-0.318^{*}$ \\
\hline Snow M & Stone Shovel U & Clay M & Cactus M \\
0.249 & $0.355^{* *}$ & $-0.284^{*}$ & $-0.316^{*}$ \\
\hline Iron Sword D & Torch M & Stone C & Stone Hoe U \\
-0.24 & $0.339^{* *}$ & 0.257 & $-0.311^{*}$ \\
\hline Honor & Idealism & Independence & Order \\
\hline Lapis Block C & Stone Sword U & The End? & Sprucewood stairs M \\
$0.336^{*}$ & $-0.335^{*}$ & $-0.371^{* *}$ & $-0.283^{*}$ \\
\hline Stone Pickaxe D & dead shrub M & The End & Iron Pickaxe C \\
$0.322^{*}$ & $-0.329^{*}$ & $-0.345^{* *}$ & -0.272 \\
\hline Torch M & Mushrooms P & powered rail P & Spruce wood stairs C \\
$0.322^{*}$ & $-0.312^{*}$ & $-0.297^{*}$ & -0.248 \\
\hline WeNeedToGo & Coal Ore M & StonePress. Plate P & Flowers P \\
$0.319^{*}$ & $-0.294^{*}$ & $-0.297^{*}$ & 0.24 \\
\hline Stone pickaxe U & Jukebox C & Dragon egg P & Stick C \\
$0.3^{*}$ & $-0.294^{*}$ & $-0.276^{*}$ & -0.226 \\
\hline Physical & Power & Romance & Saving \\
\hline Mycelium P & Redstone Ore M & Flint And Steel C & Stone Axe D \\
$0.295^{*}$ & $-0.333^{*}$ & $0.329^{*}$ & $0.323^{*}$ \\
\hline DiamondBlock P & Wood P & Glass Pane C & Iron Axe U \\
$0.283^{*}$ & $0.324^{*}$ & $0.312^{*}$ & $0.316^{*}$ \\
\hline & &
\end{tabular}

\begin{tabular}{|l|l|l|l|}
\hline $\begin{array}{l}\text { SilverfishStone C } \\
-0.276^{*}\end{array}$ & Mossy Stone M & $\begin{array}{l}\text { Nether Brick } \\
0.254\end{array}$ & $\begin{array}{l}\text { Stone Axe U } \\
0.312^{*}\end{array}$ \\
\hline Redstone Rep. C & Coal Ore M & Wool M & Chest C \\
-0.262 & -0.244 & $0.305^{*}$ & $0.311^{*}$ \\
\hline Wheat Seeds U & Dispenser P & Stone Shovel D & Sand P \\
-0.258 & -0.238 & $0.284^{*}$ & $-0.293^{*}$ \\
\hline Social & Status & Tranquility & Vengeance \\
\hline Cobblestone M & Cactus M & Fence gate C & Games quit \\
$-0.278^{*}$ & $-0.353^{* *}$ & $0.358^{* *}$ & $0.312^{*}$ \\
\hline Bookshelf C & Stone Hoe U & Fire Charge U & Silverfish Stone C \\
-0.272 & $-0.326^{*}$ & $0.308^{*}$ & $-0.308^{*}$ \\
\hline Magma cream C & Getting an Upg. & Cobblestone M & Times Played \\
-0.253 & $-0.295^{*}$ & $0.285^{*}$ & $0.303^{*}$ \\
\hline Music disk U & Fermenspider C & Gold Sword U & Redstone Torch M \\
-0.252 & $0.294^{*}$ & $0.283^{*}$ & $-0.278^{*}$ \\
\hline Coal Ore M & Cactus P & Locked chest P & Nether brick C \\
-0.249 & $-0.291^{*}$ & $-0.279^{*}$ & $-0.278^{*}$ \\
\hline
\end{tabular}

\section{NOTEWORTHY AND SURPRISING CORRELATIONS}

The research also included other variables: age, gender, declared hours of play, level of education and gaming preferences. There were some significant correlations between demographic information and game behavior: Age is negatively correlated with the number of jumps: young people seem to skip through the level. Age is negatively correlated with multiplayer joins. Young people join multiplayer games; older people tend to play alone. Women are positively correlated with glass and cakes crafted, distance swum, bows depleted. Age is positively correlated with the number of deaths, older players die more. Gaming preferences show that the more player's dedication the more it uses and crafts objects made with diamond and less objects made with stone and wood.

Some interesting facts emerge when looking at motivation factors and in-game behavior: People with strong curiosity tend to use (and reuse) more torches. They also use more stone objects. People with strong family reject the use of gold swords; it could be due to its lack of efficiency to protect people. Players with strong honor use more rail tracks and craft/use bows consistently. Players with strong idealism deal less damage and use fewer cacti. People strongly motivated by power place fewer flowers. Saving is related with the type of material used, people with strong saving tend to use "cheap materials": stone, cheap, sand, and iron and place fewer amounts of beds. People with weak saving use diamonds materials. Players reporting strong status do not use cactus but tend to use potatoes. People reporting strong vengeance tend to quit the game more times, maybe because of the few aggressive affordances provided by the game.

\section{SUPERVISED LEARNING AND PREDICTION OF MOTIVATION BASED ON BEHAVIOR}

The correlations employed hitherto in the paper have been standard Pearson product-moment correlations. While very useful for capturing linear dependencies between variables, this method cannot capture nonlinear dependencies or dependencies between more than one variable. For example, if game feature $\mathrm{X}$ was high only for 
those with very high or very low values of basic desire $\mathrm{Y}$ but not for those with intermediate values, the Pearson correlation might be very weak or zero though a strong relationship exists. Similarly, basic desire X might be high only if both game feature $\mathrm{Y}$ is high and game feature $\mathrm{Z}$ is low. Fortunately, modern machine learning contains a number of powerful methods for capturing nonlinear dependencies on several variables. Unfortunately, getting good results from these methods is not always straightforward.

In this section, we attempt to predict life motives and some additional variables such as gender from multiple ingame variables. For each personality measure we select the 20 in-game features with highest correlation to that measure, and use these as input features. Three methods for numeric prediction were used: the M5 continuous decision tree, Gaussian processes for regression and a support vector machine for regression. Weka 3.7.7 [13] was used for the experiments, and the default implementation and parameter settings for the aforementioned algorithms were used (parameter space exploration suggested that no dramatic performance increases could be achieved through simple tweaking). All reported accuracy values are based on 10fold cross-validation.

Table 6 lists a number of life motives and our best results in trying to predict them from in-game data. For each basic desire, the lowest relative absolute error found is listed (where predicting the mean has $100 \%$ error and perfect prediction $0 \%$ error, lower is better) and the highest correlation between the output of the predictor and the target function. Different methods performed best depending on which variable was being predicted.

As can be seen from this table, gender is the easiest variable to predict, though it must be pointed out that the data set is highly skewed with regards to this variable. Age and actual number (though not reported number) of hours played can also be predicted reasonably well. Of the life motives, honor, romance, independence and acceptance are the most predictable using these methods. We were not able to predict idealism, tranquility nor vengeance better than the baseline. Comparing table 6 with table 4 paints a rather conflicting picture. While the most predictable trait, honor, indeed had more and stronger correlations with in-game statistics than expected, romance and independence have not. Curiosity, which has the highest number of significant correlations, cannot be predicted much better than social contact, which has a third as many correlations. One possible explanation for this is that the machine learning methods employed here do better on some relations than other; another possible explanation is that there are strong inter-correlations between the features correlated with e.g. curiosity, diminishing the value of combining them. It should be pointed out that for most traits the learning algorithms used managed to learn functions that correlate better with the target variable than do any of the individual features (the exceptions are idealism, tranquility and vengeance), i.e., they work.

TABLE VI

Prediction of Life Motives

\begin{tabular}{|l|l|l|}
\hline Gender & 51.2 & 0.573 \\
\hline Age & 69.0 & 0.728 \\
\hline Hours played (metric) & 70.6 & 0.678 \\
\hline Honor & 73.2 & 0.594 \\
\hline Romance & 78.6 & 0.687 \\
\hline Independence & 79.7 & 0.581 \\
\hline Acceptance & 79.8 & 0.574 \\
\hline Power & 82.2 & 0.636 \\
\hline Education & 83.0 & 0.333 \\
\hline Eating & 84.5 & 0.598 \\
\hline Family & 88.8 & 0.582 \\
\hline Saving & 88.9 & 0.531 \\
\hline Curiosity & 89.8 & 0.382 \\
\hline Status & 90.9 & 0.429 \\
\hline Social & 93.0 & 0.346 \\
\hline Physical & 95.1 & 0.303 \\
\hline Hours played (declared) & 97.6 & 0.226 \\
\hline Idealism & 100.0 & 0.164 \\
\hline Tranquility & 100 & 0.397 \\
\hline Vengeance & 106.6 & 0.126 \\
\hline & & \\
\hline
\end{tabular}

\section{DISCUSSION}

As discussed in section V.C., the number of significant correlations in the data was not much higher than would be expected using a binomial calculation. However, when looking at individual life motives, several of them have far more significant correlations than would be expected, making it statistically extremely improbably that all (or even the majority) of correlations with curiosity, honor, saving and vengeance should be spurious. Additionally, it should be noted that from the 546 Minecraft features, many are essentially arrays of zeroes, as they count very unusual activities that most players do not engage in. Naturally, these are not correlated with anything. If all features which had more than half of their instance values set to zero are removed, the number of expected significant correlations shrinks dramatically but the number of actual significant correlations do not, validating our conviction that the vast majority of the correlations we see are not spurious. As can be seen from Table 2, Minecraft players in our survey differ from the population at large, being substantially more curious and idealistic and substantially less vengeful and status-driven. Curiously, it seems that those personal motives that have the highest numbers of correlations to ingame data are also those that differ most from the mean, though the number of features is too small to draw any certain conclusions from this. There is as far as we know no a-priori reason for such a relation, and we do not have a plausible explanation.

\section{CONCLusion}

Motivation factors have shown to be strongly correlated 
to in-game behavior. Some motives are stronger and more present than others in players' surveys; this could be because Minecraft has better affordances to express certain motivations or because a certain type of players chose to play the game. It could be that the ludo-aesthetic affordances offered by the game attract a certain type of player. It would seem like Minecraft pre-selects curious people as its players but maybe only curious people chose to participate to the study. Either way it is clear that not all motivation factors are equally captured by behavior in the game. The mean motivation profile for Minecraft players shows considerable drive towards Curiosity, Saving, Independence, Honor and Idealism, while not being at all interested in Acceptance or Status. Interestingly enough Curiosity, Saving, Honor and Idealism show higher number of correlations than any of the other 16 facets of motivations while Acceptance and Status record a significantly lower than average number of correlations. The only factor of motivation that does not follow this trend is Independence. The number of correlations per factor of motivation mirrors very closely the mean value reported by players in the survey. Even if the game features that are correlated to motivational factors are not exactly homogeneous across all players, the number of correlations in itself seems to be an accurate predictor of strong or weak life motives.

\section{REFERENCES}

[1] Bandura, A. (1982). Self-efficacy mechanism in human agency. American Psychologist, 33, 344-358.

[2] Bandura, A. (1986). Social Foundations of Thought and Action. Englewood Cliffs, NJ: Prentice-Hall.

[3] Bandura, A. and Cervone, D. (1986). Differential engagement of selfreactive influences in cognitive motivation. Organizational Behavior and Human Decision Processes, 38, 92-113.

[4] Borbora, Z. Srivastava, J. Kuo-Wei Hsu and Williams, D. (2009). Churn Prediction in MMORPGs Using Player Motivation Theories and an Ensemble Approach. Privacy, security, risk and trust (passat), 2011 ieee third international conference on and 2011 ieee third international conference on social computing (socialcom). P. 157-164

[5] Bowman, M., Debray, S. K., and Peterson, L. L. 1993. Reasoning about naming systems. ACM Trans. Program. Lang. Syst. 15, 5 (Nov. 1993), 795-825. DOI= http://doi.acm.org/10.1145/161468.16147.

[6] Canossa, A. 2012 Give me a Reason to Dig: Qualitative Associations Between Player Behavior in Minecraft and Life Motives. Foundation of Digital Games, Raleigh, 2012

[7] Costa, P.T. Jr. and McCrae, R.R. (1992). Revised NEO Personality Inventory (NEO-PI-R) and NEO Five-Factor Inventory (NEO-FFI) manual. Odessa, FL: Psychological Assessment Resources.

[8] Deci, E. L. and Ryan, R. M. (1985). Intrinsic motivation and selfdeterminaton in human behaviour. New York: Plenum.

[9] Ding, W. and Marchionini, G. 1997. A Study on Video Browsing Strategies. Technical Report. University of Maryland at College Park.

[10] Drachen, A. and Canossa A. 2009 Towards gameplay analysis via gameplay metrics. Proceedings of the 13th International MindTrek Conference: Everyday Life in the Ubiquitous Era. ACM. New York.USA. P.202-209

[11] Drachen, A. Canossa, A. and Yannakakis, G.N. 2009 Player modeling using self-organization in tomb raider: underworld. Proceedings: CIG'09 Proceedings of the 5th international conference on Computational Intelligence and Games. IEEE Press Piscataway, NJ, USA. P.1-8

[12] Goldberg, L. R. (1981). Language and individual differences: The search for universals in personality lexicons. In Wheeler (Ed.), Review of Personality and social psychology, Vol. 1, 141-165. Beverly Hills, CA: Sage.

[13] Hall, Mark, Eibe Frank, Geoffrey Holmes, Bernhard Pfahringer, Peter Reutemann, and Ian H. Witten. "The WEKA data mining software: an update." ACM SIGKDD Explorations Newsletter 11, no. 1 (2009):

[14] Havercamp, S. M. and Reiss, S. 2003 A Comprehensive Assessment of Human Strivings: Test-Retest Reliability and Validity of the Reiss Profile, Journal of Personality Assessment 2003, Vol. 81, No. 1, pp. 123-132.

[15] Herzberg, F., Mausner, B. and Snyderman, B.B. 1959, The Motivation to Work. John Wiley. New York.

[16] Mahlmann, T. Drachen, A. Togelius, J. Canossa, A. and Yannakakis, G.N. 2010. Predicting player behavior in Tomb Raider: Underworld. Computational Intelligence and Games (CIG). P.178-185

[17] McCrae, R.R, and John, O.P 1990. An introduction to the Five-Factor model and its applications.

[18] Reiss, S. (2008) The Normal Personality, A New Way of Thinking about People. Cambridge University Press, 2008

[19] Reiss, S. and Haverkamp, S. M 1998. Towards a Comprehensive Assessment of Fundamental Motivation: Factor Structure of the Reiss Profiles Psychological Assessment 1998, Vol. 10, No. 2, pp. 97-106.

[20] Ross J. Quinlan 1992 Learning with Continuous Classes. In: 5th Australian Joint Conference on Artificial Intelligence, Singapore, 343348, 1992.

[21] Ryan, R. M. and Deci, E. L. (2000). Self-determination theory and the facilitation of intrinsic motivation, social development, and well-being. American Psychologist, 55, 68-78.

[22] Shevade, S.K. Keerthi, S.S. Bhattacharyya, C. and Murthy K.R.K. 1999 Improvements to the SMO Algorithm for SVM Regression. In: IEEE Transactions on Neural Networks, 1999

[23] Yee, N. (2005). Motivations of Play in MMORPGs. DIGRA 2005, Vancouver, June, 2005.

[24] Yee, N. (2006). The Demographics, Motivations and Derived Experiences of Users of Massively-Multiuser Online Graphical Environments. PRESENCE: Teleoperators and Virtual Environments, 15, 309-329.

[25] Yee, N. (2006). Motivations of Play in Online Games. CyberPsychology and Behavior, 9, 772-775.

[26] Yee, N. Ducheneaut, N. Nelson L. and Likarish, P. 2011: Introverted elves \& conscientious gnomes: the expression of personality in world of warcraft. Proceedings of the 2011 annual conference on Human factors in computing systems, 753-762.

[27] Yee, N. Harris, H. Jabon, M.and Bailenson, J.N. (2010). The Expression of Personality in Virtual Worlds. Social Psychology and Personality Science. Published online before print August 6, 2010.Social Psychological and Personality Science January 2011 vol. 2 no. 1 P. 5-12

[28] van Lankveld G. Schreurs, S. and Spronck P. 2009 Psychologically Verified Player Modelling. GAMEON 2009: P.12-19

[29] van Lankveld G. Schreurs, S. Spronck P. van den Herik H.J. 2010 Extraversion in Games. Computers and Games 2010. P. 263-275

[30] van Lankveld, G. Spronck, P. van den Herik, H.J. and Arntz, A. 2011. Games as Personality Profiling tools. Computational Intelligence and Games (CIG), 2011 IEEE P.197-202

[31] Minecraft, Mojang, Mojang, 2011

[32] Atkinson, J. W. 1965 An Introduction to Motivation, D. Van Nostrand Company, Inc. Oxford, England:

[33] Atkinson, J. W. and Raynor, J. O. 1978 Personality, Motivation and Achievement, Hemisphere Pub. Corp.

[34] Reiss, S. 2009 The Myths of Intrinsic-Extrinsic Motivation Psychology Today, November 202009 http://www.psychologytoday.com/blog/who-we-are/200911/the-mythsintrinsic-extrinsic-motivation accessed 5th December 2012

[35] Maslow, A. H. 1970 Motivation and Personality. Harper \& Row

[36] Yannakakis, G. N. and Togelius, J. 2011 Experience-driven Procedural Content Generation. IEEE Transactions on Affective Computing.

[37] Smith, A. M., Lewis, C., Hullett, K. et al. 2011 An Inclusive View of Player Modeling. In Proceedings of the 6th International Conference on the Foundations of Digital Games (FDG 2011).

[38] Spronck, P., Balemans, I. and van Lankveld, G. 2012. Player Profiling with Fallout 3. AIIDE 2012 conference

[39] Williams, D., Consalvo, M., Caplan, S. and Yee, N. 2009 Looking for Gender: Gender Roles and Behaviors Among Online Gamers, Journal of Communications, Volume 59, Issue 4, pages 700-725, December 2009. 